\title{
LOCATION MODEL OF SPECIALIZED TERMINALS FOR SOYBEAN EXPORTS IN BRAZIL
}

\author{
Alessandra Fraga Dubke ${ }^{1}$ and Nélio Domingues Pizzolato ${ }^{2 *}$
}

Received August 2009 / Accepted June 2010

\begin{abstract}
The purpose of this work is the development of a location model for specialized terminals used as transshipment points in the supply chain of soybeans. The theoretical basis of the study relies on the association of a transshipment model with a multi-commodity, multi-facility capacitated location model. The shipping ports might be seen as specialized terminals that add value to the exported products by transforming raw soy grains into soy oil and soy meal. The proposed model also considers service activities in each terminal and the capacity of the maritime ports. Using representative data from the year 2004, the model is illustrated by a small case study, which considers six points of production in inland Brazil, all served by railways, one maritime port on the north and five on the east coast, and three destination ports in Europe and Asia. The study includes a rough sensitivity analysis regarding volumes, capacities, prices, and transportation costs.
\end{abstract}

Keywords: facility location models, specialized terminals, logistic platforms and transshipment.

\section{INTRODUCTION}

The present world food crisis is granting Brazil a unique opportunity, seen by some rather as a responsibility toward humankind, to raise the international supply of grains. In fact, considering its extensive geographic size huge areas might potentially be converted into productive plantations. Vast unproductive areas exist all over the country, mostly resulting from extensive cattle raising, an early and outdated economic activity historically responsible for the expansion of the country beyond its prediscovery defined limits, stated by the Tordesillas treaty in the 15th century, two years after the Colombus trip to America, which divided between Portugal and Spain the new world yet to be discovered. This ancient business has evolved mostly in inland regions of the country, especially those covered by the Cerrado Biome. Such areas had no European occupation but were rather inhabited by local Indians of the same strata as those living on the east coast of the continent. This Biome is shown by the enhanced section of the country in

\footnotetext{
*Corresponding author

${ }^{1}$ IFES and VALE. E-mail: alessandradubke@gmail.com; alessandra.dubke@vale.com

${ }^{2}$ PUC-Rio. E-mail: ndp@puc-rio.br
} 
Figure 1a. It is basically similar to the African and North American savannah, covers about one fourth of the country and used to be rated as inappropriate for intensive cultivation.

However, systematic research projects carried out by the Brazilian Agricultural Research Corporation (EMBRAPA), a national state owned research company, have found economical ways to turn the Cerrado into extremely highly productive area. As a consequence, fertile and inexpensive land has been put into production and currently Brazil is the fourth largest grain producer in the world. According to the National Company of Food Supply (CONAB, 2008), the United States Department of Agriculture (USDA, 2008) and EMBRAPA (2002), it is estimated that for the period of 2007/2008 the biggest grain producers in million tonnes per year (Mtpy) shall be USA (482), China (440), India (237), and Brazil (143). What is specific to Brazil is that, in contrast with the three other countries, remarkable productivity rates and the still very large unexploited land extensions, estimated at 90 million hectares - almost as large as the present 92 million hectares in use for production in the USA - allow for a realistic prediction that Brazilian grain production might reach 300 million tons by the year 2018. It is also important to remark that, since its meat production derived from cattle herds is based on grazing fields, at least half of the grains might be available for exports. Figure $1 \mathrm{~b}$ indicates the incidence of soybean production, and confirms the predominance of the Cerrado territory in the Brazilian soybean production.

It seems clear to everyone that the existence of limits to growth should be recognized, and common sense suggests that food production ought to increase through further technological improvements and recuperation of improperly managed areas rather than occupation of new areas which would better remain untouched to preserve the environment, wild life, indigenous reserves, and the fragile ecological balance. This is indeed a sensitive problem, source of political conflicts between several segments of the society. Fortunately, in our view, the predominant trend is to enforce protection over the multiple existing biomes.

On the other hand, the main production areas are significantly far from the ocean coast, and means of transportation are quite primitive, lacking railways and relying mostly on old trucks and poorly paved routes. It is currently affirmed that the downstream logistics costs for grain producers offset the economical advantages they have in producing at lower costs. In addition, it ought to be said that other elements of the logistics structure are also deficient. During the harvesting period, for instance, transportation tariffs are higher and market prices depressed. If the soybeans are warehoused or transformed to two more valuable byproducts such as soy oil and soy meal the producer might take advantage of lesser tariffs and higher prices. The focus of the present study lies exactly on improving the competitiveness of the product, and we expect to contribute to rethink the logistics of the entire supply chain.

In terms of strategic decisions, the general objective of the present study is the development of a capacitated location model for specialized terminals using the traditional transshipment model, combined with multi-commodity and multi-facility network flows. The specific objective is to propose a model for a supply chain in the agribusiness sector that might require a specialized 

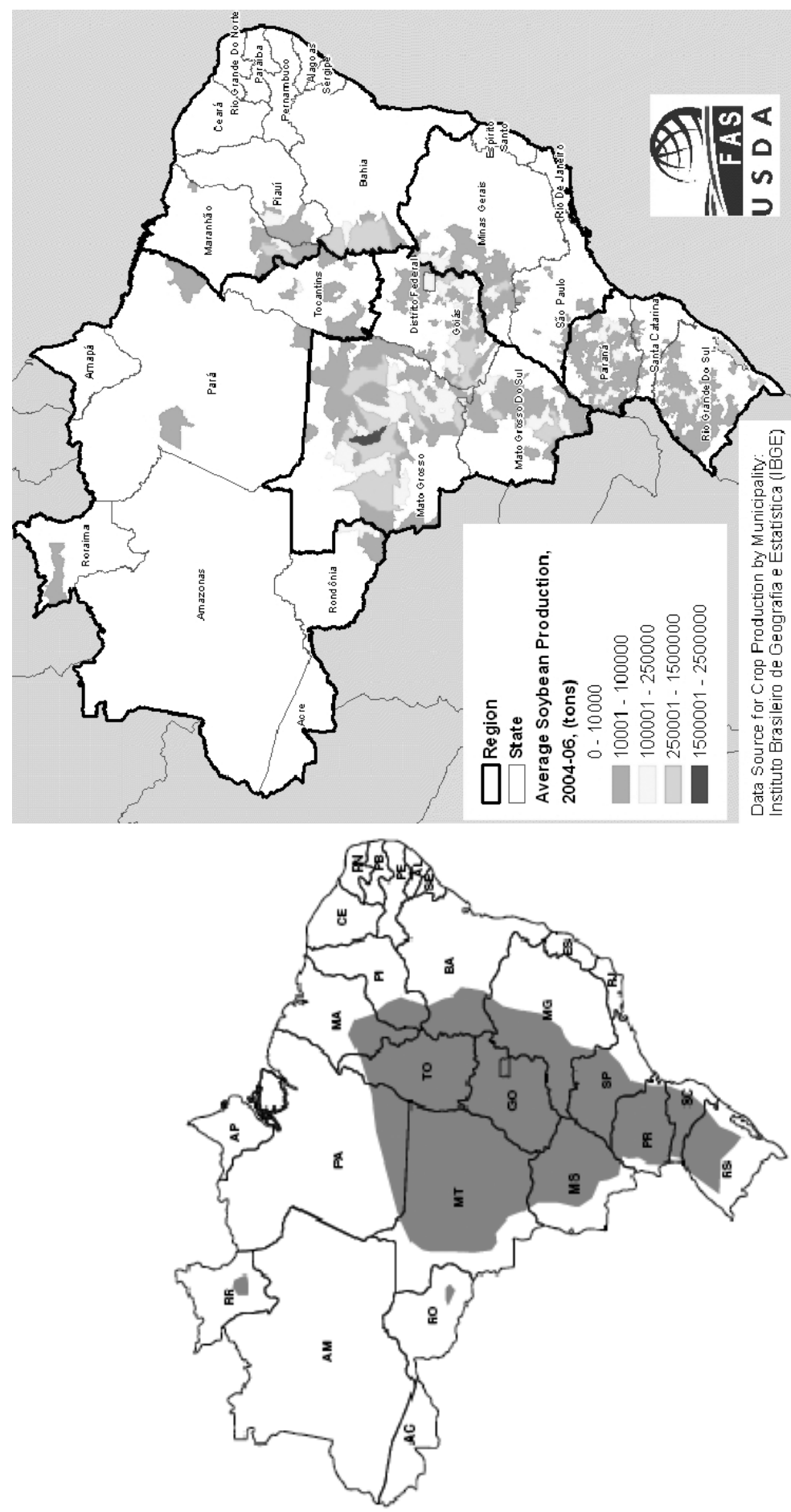

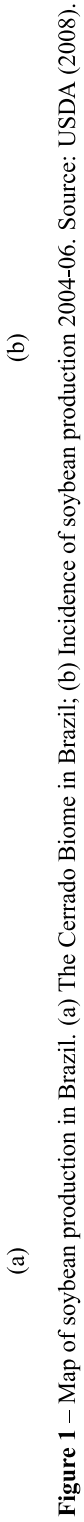


transshipment terminal to handle the flow of these products and to support its transformation in the two mentioned byproducts. In addition, using real statistical data this study has developed a case study in which the supply chain of soybeans is examined.

According to ReVelle \& Eiselt (2005), location analysis refers to the modeling, formulation, and solution of a class of problems that can be best described as positioning facilities in a given space. We can supplement this by noting that when the proposed facility is embedded in a supply chain it becomes a logistics center which provides services and adds value to the product. Its corresponding economic evaluation involves strategic decisions, choice of transportation modes, choice of suppliers, production scheduling, distribution decisions, and so on. Such facilities are currently known as logistics platforms or specialized terminals, depending on the level of services or transformations eventually applied to the products.

Traditional references on facility location problems are: Weber (1909); Brandeau \& Chiu (1989); Sidharan (1995); ReVelle \& Laporte (1996); Canel \& Khumawala(1996); Crainic \& Laporte (1997); Owen \& Daskin (1998); Drezner \& Hamacher(2002); and Harkness \& ReVelle (2003). Among other related references, optimization problems concerning multi-commodity facility location have been modeled by Hu (1963); Ahuja (1993); Pirkul \& Jayaraman (1998), and location associated to transshipment problems have been studied by Campbell (1993); Konings (1996); Sharma et al. (2003), and Matisziw (2005).

Briefly, logistics platforms are integrated facilities that offer a variety of value added services in terms of information, transportation or specific services to the physical product, which are of interest to a large number of producers, transporters, users, workers and clients. Logistics platforms are normally located at intersections of main streams of flows, comprised by roads, railways, and maritime ports. This is done in order to encourage the best use of the existing transportation infrastructure, especially railways and waterways, which are less flexible but more economical. Therefore, logistics platforms are designed to combine the cargo stream of shippers along international logistics corridors.

Specialized terminals, in turn, are logistics units usually based around urban centers, industrial parks, ports, and airports, that are able to provide services such as postponement and a number of other value adding functions to the products. These terminals can be understood as less complex than logistics platforms and they tend more often to target a single class of products to which their services are applied.

In the sequence, Section 2 exemplifies the use of logistics platforms or specialized terminals, and shows the importance of soybeans to Brazil and their role in the world market. Section 3 proposes a location allocation model combined with transshipment and value added services. Using real data and a small but representative network of the huge strategic problems facing the exports of soy products in Brazil, Section 4 presents the results of the application of the model including a basic sensitivity evaluation, while Section 5 sketches some conclusions. 


\section{LOGISTICS STRATEGY AND THE SOYBEANS MARKET}

According to Izquierdo (1994), a logistics platform can be defined as: “... a set of installations and equipments - infrastructure and transportation - in which different activities are performed directly related to national and international transportation, that may be used conjointly by industries and distributors, and offers a series of complementary services to different clients transportation firms, industries, warehousing and brokers. In the platform, transshipment, bulk consolidation and modal transfers of goods are carried out and goods might be warehoused or subjected to transformation and finishing". In addition, the author describes intervening criteria for the design of such centers, which include area, location, market potential, environmental impact, and functional organization. Among these conditions, the physical location for either national or international distribution seems to be the main deciding factor. For third party logistics providers, centrality regarding distances to the main markets appears to be the dominating factor.

In the study made by Tanigushi et al. (1999), a location model with optimal size for Osaka in Japan is proposed. Special emphasis is placed on the concept of public logistics terminals as complex facilities with multiple functions including transshipment yards, warehousing, wholesale markets, information centers and display of products. The author also mentions that this idea is derived from similar terminals installed in Holland and Germany but the matter requires a broader investigation, especially concerning size, function, location, and the public sector management of such centers. Therefore, the application might be implemented in public or private harbor areas, as well as in urban areas, especially in the vicinity of consumption centers.

Around the world, depending on each country, different but equivalent denominations for the existing public and private logistics platforms are in use, such as: Centrales Integradas de Mercancias (CIM), in Spain; Plateformes Logistiques Publiques and Distriport, in France, Belgium and Holland; Distripark, in Singapore and Belgium; Freight Village, in England; Interporti, in Italy; Guterverkehrszentren (GVZ), in Germany; Integrated Logistics Centers - Intermode Terminals or Logistics Platforms in Brazil; Maquiladoras, in México; Load Centers, in USA; Integrated Centres for the Transshipment, Storage, Collection and Distribution of Goods (TSCD), in Holland, in addition to traditional distribution centers - DC, break-bulk terminals, transshipment terminals and Logistics Activity Areas (Hayut, 1981; and Konings, 1996).

The soybean cropping was introduced in the south of Brazil in the year 1963 and since then its production has steadily grown at an average rate of 5.28\% a year as a result of good prices and two technical factors. One of these factors was the adaptation of the plant to other regions, especially the Cerrado area in the center of the country, and the second was the impressive $4.59 \%$ average yearly increase in its productivity, today one of the largest in the world, (BNDES, Social and Development National Bank, 2004). Most of the soybean production in South America is harvested in Brazil and Argentina, but it is also expanding in Paraguay, Bolivia and Ecuador. Together, North and South America are responsible for $85 \%$ of the world's soybean production. Table 1 shows the world's soy production and consumption by main countries. In particular, $90 \%$ of the total production is concentrated in four countries, while most of the consumption occurs in the same four countries plus the European Union. 
Table 1 - Soy production and consumption.

\begin{tabular}{|l|c|c|c|c|c|c|c|}
\hline \multicolumn{1}{|c|}{$\begin{array}{c}\text { World inicial } \\
\text { stock (Mtpy) }\end{array}$} & $\begin{array}{c}2001 / 02 \\
\mathbf{3 4 . 2}\end{array}$ & $\begin{array}{c}2002 / 03 \\
\mathbf{2 8 . 3}\end{array}$ & $\begin{array}{c}2003 / 04 \\
\mathbf{3 6 . 1}\end{array}$ & $\begin{array}{c}2004 / 05 \\
\mathbf{4 3 . 6}\end{array}$ & $\begin{array}{c}2005 / 06 \\
\mathbf{3 7 . 8}\end{array}$ & $\begin{array}{c}2006 / 07 \\
\mathbf{4 7 . 5}\end{array}$ & $\begin{array}{c}2007 / 08 \\
\mathbf{5 3 . 3}\end{array}$ \\
\hline Production (Mtpy) & $\mathbf{1 8 4 . 8}$ & $\mathbf{1 9 6 . 8}$ & $\mathbf{1 8 6 . 6}$ & $\mathbf{2 1 5 . 8}$ & $\mathbf{2 2 0 . 5}$ & $\mathbf{2 3 6 . 6}$ & $\mathbf{2 1 8 . 8}$ \\
EUA & 79.6 & 75.0 & 66.8 & 85.5 & 84.3 & 86.8 & 70.4 \\
Brazil & 41.5 & 51.4 & 49.9 & 52.0 & 52.3 & 58.4 & 58.9 \\
Argentina & 28.0 & 35.2 & 33.0 & 39.0 & 40.5 & 44.0 & 45.5 \\
China & 15.3 & 16.5 & 15.4 & 17.4 & 16.4 & 16.2 & 16.2 \\
\hline Consumption (Mtpy) & $\mathbf{1 8 4 . 5}$ & $\mathbf{1 9 1 . 4}$ & $\mathbf{1 8 9 . 3}$ & $\mathbf{2 0 4 . 8}$ & $\mathbf{2 1 5 . 3}$ & $\mathbf{2 2 5 . 2}$ & $\mathbf{2 3 3 . 5}$ \\
EUA & 46.3 & 44.0 & 41.6 & 44.9 & 47.3 & 49.2 & 50.1 \\
China & 20.3 & 26.5 & 25.4 & 29.0 & 34.5 & 37.0 & 37.5 \\
European Union & 19.2 & 17.9 & 15.7 & 16.8 & 17.8 & 18.0 & 19.5 \\
Brazil & 24.7 & 27.2 & 29.3 & 29.6 & 30.4 & 33.5 & 35.1 \\
Argentina & 20.9 & 23.5 & 25.0 & 25.3 & 32.0 & 35.0 & 35.0 \\
\hline Final stock (Mtpy) & $\mathbf{3 4 . 5}$ & $\mathbf{3 3 . 7}$ & $\mathbf{3 3 . 4}$ & $\mathbf{5 4 . 6}$ & $\mathbf{4 3}$ & $\mathbf{5 8 . 9}$ & $\mathbf{3 8 . 6}$ \\
Stock/consumption & $19 \%$ & $18 \%$ & $18 \%$ & $27 \%$ & $20 \%$ & $26 \%$ & $17 \%$ \\
\hline
\end{tabular}

Source: CONAB (2008), CVRD (2005), and USDA (2008).

Soybean production in Brazil might reach 140 million tons by the year 2020 if both the present expansion rate and the productivity increase rate are maintained. Nowadays, local consumption in Brazil reaches 35 million tons, which allows a significant surplus of almost half the total production for exports. Argentina and the USA might obtain production rates of, respectively, 100 and 110 million tons by the same time. Certainly, these volumes depend on international prices, which define incentives to farmers.

Prices are determined by the international markets. Statistical data collected by Siqueira (2004) indicate that in the last few years the average prices per ton have been US\$ 190 in 2000, US\$ 174 in 2001 and US\$ 190 in 2002. In the following years, market prices have been increasing consistently, reaching US\$290 for grains, US\$220 for soy meal, and US\$ 600 for oil in 2004. Souza et al. (2010) have estimated for the period 2009-2018 the Brazilian production, consumption, exports and export prices for raw soy beans, soy oil and soil meal. The study asserts a great growth perspective for the country in the world markets.

The logistics infrastructure for soybean exports is composed of ports, warehouses and specialized terminals. Using maritime ports, about $95 \%$ of the exports are directed to Europe and Asia, while rail and road transportation are used for the Mercosul countries. The weakness of the supporting infrastructure for soy transport is considered the bottleneck of the sector. Such infrastructure flaws seriously affect the competitiveness of the product, since they offset the lower production cost advantage. De Paula \& Faveret (2000) have pointed out six main factors responsible for swelled transport cost and the consequent loss of competitiveness of the grains produced in the Cerrado area, which are very distant from the maritime ports. These factors are:

- Almost $60 \%$ of the cargo transport in Brazil is made by roads and using trucks.

- Lack of investment in the road networks. 
- The increasing production in inner areas of the country accentuates the dependence on roads.

- The aging trucks being used generate costs to its operators, which charge higher tariffs.

- The road carrier sector is predominantly composed by thousands of independent truck drivers which require direct negotiation and anticipated payments for the transport service.

- Despite increasing investments, other possible means of transportation, such as railroads or rivers, have not become effective alternatives to road transportation due to their lack of flexibility and limited capacity.

The predominance of trucks in Brazil is attributed to topographical, historical and economical factors whose justification will not be addressed here. The consequence is that most of the new inland production frontiers, which are far away and naturally isolated from the sea coast, are not adequately accessible, except, as already mentioned, by poorly maintained roads and aged trucks. Railroads are generally scarce but whenever they are available, the trucks have the function of collecting the production at the farms and taking it to a rail terminal. It is interesting to compare Brazil with Argentina, a neighboring country and a major competitor in soybean production. In Argentina, most of the volume of soybeans is transported by trucks over relatively short distances between the production areas and the city of Rosario on the banks of the Parana River, from where the cargo is shipped to Buenos Aires or directly to Europe and Asia. Therefore, we might say that Brazil depends on trucks over large distances, while Argentina uses more trucks over much shorter distances.

Regarding the sea ports, the flow of soybeans is traditionally directed to ports in the south or southeast region and more recently to ports in the north of the country. The main ports in the south are Rio Grande and São Francisco do Sul; in the southeast they are Santos, Paranaguá, and Vitória. When the exports flow north they use Manaus, reached exclusively by rivers, Ponta da Madeira or Itaqui, reached by either railways or rivers. Concerning ports, a recurrent problem in Brazil since the country was in this particular not well contemplated by nature, the main factors that affect their competitiveness are:

- Tariff costs.

- Demand satisfaction, limited by the restricted capacity of terminals and warehouses.

- Congestion of ships and trucks during the peak of the harvest season, seriously affecting the flow of grains.

- Lack of investment to expand the ports' facilities.

- Limitations on the draft of most of the ports, restricting the access only to smaller ships.

\section{MODEL FORMULATION}

The installation of specialized terminals in areas surrounding existing ports and private terminals could be a starting point to fulfill specific demands of the soy export chain. It would allow 
speeding up to the process, creating value added services, and making the supply chain more competitive internationally.

The model proposed below is fundamentally based on the classical transshipment model, in which the chosen locations, i.e., the port terminals, play the role of transshipment points to the final destinations. In addition, the proposed model includes the eventual application of a certain number of services able to add value to the incoming products, both in the form of time value, such as storage, or in the form of physical change, such as smashing and processing. By the same token, it is to note that if for a given solution no kind of value added service is applied, the model reduces to the transshipment model and the solution turns out to be always composed by integer numbers.

The general problem of locating a logistics platform or specialized terminal considers a set of $J$ potential locations; a set $I$ of points of origin; a set $K$ of points of destination; a set $M$ of inputs; a set $Q$ of products or commodities; and a set $S$ of services. In the case of soybeans, the services provided in specialized terminals might include transshipment, segregated warehousing, smashing (a process that transforms soybeans in soy meal) and processing (oil refining), besides discharging and shipping services. Certainly, these services add value to the entire soybean supply chain.

The parameter $C_{i j m}^{i n}$ represents the cost of inbound transportation of the input $m$ from origin $i$ to a specialized terminal $j$, and the parameter $C_{j k q}^{o u t}$ represents the outbound cost of transportation of the product $q$ from a specialized terminal $j$ to destination $k$.

For each specialized terminal or port $j \in J$, there is a fixed cost $f_{j}$ for its installation, a fixed $\operatorname{cost} g_{j s}^{\text {serv }}$ referring to opening the service $s$ in this terminal, and a cost $\alpha_{j s m}^{\text {serv }}$ which varies as a function of the volume of the input $m$ that uses the service $s$ of this terminal. Ports $j$ are capacitated facilities which have a total capacity $W_{j}$ and an installed capacity $w_{j s}$ of service $s$. Capacity flows between a given origin-destination pair have been ignored. The congestion commonly observed tends to happen during the harvesting period and is a consequence of the lack of warehousing at every origin; if this problem is solved, smaller tariffs and a more smooth flow would be attained.

There is also a commercialization price $P_{k q}$ for product $q$ at destination $k$, a volume $S_{i m}$ of the input $m$ offered at the origin $i$, a volume $D_{k q}$ of the product demanded at the destination $k$, and a coefficient $\beta_{j s m q}$ for inputs that are altered in their volumes if they are turned into by products $q$, depending on the kind of service $s$ applied in the terminal $j$. In addition, the parameter $Z$ indicates the number of terminals that will be opened.

The decision variables of the model are: $X_{i j s m}^{i n}$, representing the flow of input $m$ sent from the point of origin $i$ to the terminal $j$ to be subjected to the service $s ; X_{j k s q}^{\text {out }}$, representing the flow of product $q$ that has received the service $s$ in the terminal $j$ and is directed to destination $k$; $Y_{j}=1$, indicating the decision to open a terminal in the location $j$ while $Y_{j}=0$, otherwise; and $Y_{j s}^{\text {serv }}=1$, defining the decision to offer the service $s$ in the terminal $j$ and $Y_{j s}^{\text {serv }}=0$, otherwise. The objective of this model is to decide, for a given supply chain, which logistics terminals should be opened and also to assign the corresponding inbound and outbound flows to these platforms 
in order to maximize the total profit for the supply chain. In summary, the relevant sets of points, parameters and decision variables for the general model are as follows:

\section{Sets:}

$I \quad$ Set of points of origin $i$ (cities, plants, cooperatives, terminals or distribution centers)

$J \quad$ Set of specialized terminals $j$ (located in public sea ports or private terminals)

$K \quad$ Set of points of destination $k$ (maritime terminals)

$M \quad$ Set of inputs $m$

$Q \quad$ Set of products $q$

$S \quad$ Set of services $s$

\section{Parameters of the model:}

$P_{k q} \quad$ Price of the product $q \in Q$ sold to destination $k \in K$

$C_{i j m}^{i n} \quad$ Cost of transporting input $m \in M$ from origin $i \in I$ to the terminal $j \in J$

$C_{j k q}^{\text {out }} \quad$ Cost of the transporting the product $q \in Q$ from the specialized terminal $j \in J$ to destination $k \in K$

$f_{j} \quad$ Fixed cost of installation of a specialized terminal $j \in J$

$g_{j s}^{\text {serv }} \quad$ Fixed cost to open the service $s \in S$ in the specialized terminal $j \in J$

$\alpha_{j s m}^{s e r v} \quad$ Variable cost of the package of services $s \in S$, applied to the input $m \in M$ in the specialized terminal $j \in J$

$\beta_{j s m q} \quad$ Change of volume coefficient by service $s \in S$ and input $m \in M$

$\mathrm{w}_{j s} \quad$ Nominal service capacity of the service type $s \in S$ in terminal $j \in J$

$W_{j} \quad$ Total capacity in the specialized terminal $j \in J$

$Z \quad$ Maximum number of opened specialized terminals

$S_{i m} \quad$ Supply of inputs $m \in M$ at the origin $i \in I$

$D_{k q} \quad$ Maximum demand for the product $q \in Q$ at destination $k \in K$

\section{Decision variables:}

$Y_{j} \quad \begin{cases}1, & \text { if the specialized terminal is opened in location } j \\ 0, & \text { otherwise }\end{cases}$

$Y_{j s}^{\text {serv }} \begin{cases}1, & \text { if the service } s \text { is offered at the location } j \\ 0, & \text { otherwise }\end{cases}$

$X_{i j s m}^{i n} \quad$ Quantity of the input $m$, assigned from origin $i$ to the specialized terminal $j$, to receive the service $s$

$X_{j k s q}^{\text {out }} \quad$ Quantity of product $q$ that was subjected to the service $s$ in the specialized terminal $j$ with destination $k$ 
The proposed model becomes:

$$
\text { Maximize } \begin{aligned}
& \sum_{j \in J} \sum_{k \in K} \sum_{q \in Q} \sum_{s \in S} P_{k q} X_{j k s q}^{\text {out }} \\
& -\sum_{j \in J}\left\{\sum_{i \in I} \sum_{m \in M} C_{i j m}^{\text {in }} \sum_{s \in S} X_{i j s m}^{\text {in }}\right\} \\
& -\sum_{j \in J}\left\{f_{j} Y_{j}+g_{j s}^{\text {serv }} Y_{j s}^{\text {serv }}+\sum_{s \in S} \sum_{m \in M} \sum_{i \in I} \alpha_{j s m}^{\text {serv }} X_{i j s m}^{\text {in }}\right\} \\
& -\sum_{j \in J}\left\{\sum_{k \in K} \sum_{q \in Q} C_{j k q}^{\text {out }} \sum_{s \in S} X_{j k s q}^{\text {out }}\right\}
\end{aligned}
$$

$$
\begin{aligned}
& \text { Subject to } \sum_{j} \sum_{s} X_{i j s m}^{i n} \leq S_{i m} \quad \forall i \in I, m \in M \\
& \sum_{j} \sum_{s} X_{j s k q}^{\text {out }} \leq D_{k q} \quad \forall k \in K, q \in Q \\
& \sum_{m} \sum_{i} X_{i j s m}^{i n} \leq w_{j s} Y_{j s}^{s e r v} \quad \forall j \in J, s \in S \\
& \sum_{s} \sum_{m} \sum_{i} X_{i j s m}^{i n} \leq W_{j} Y_{j} \quad \forall j \in J \\
& \beta_{j s m q} \sum_{i} X_{i j s m}^{i n}-\sum_{k} X_{j s k q}^{\text {out }}=0 \quad \forall j \in J, s \in S, m \in M, q \in Q \\
& \sum_{j} Y_{j} \leq Z \quad \forall j \in J
\end{aligned}
$$

$$
\begin{array}{ll}
X_{i j s m}^{i n}, X_{j k s q}^{\text {out }} \geq 0 & \forall i \in I, j \in J, s \in S, \\
& k \in K, m \in M, q \in Q \\
Y_{j} \in\{0,1\} & \forall j \in J, s \in S \\
Y_{j s}^{\text {serv }} \in\{0,1\} & \forall j \in J, s \in S
\end{array}
$$

The problem consists of finding the subset of specialized terminals that maximize the total profit of the system while satisfying the amounts supplied from each origin. Constraint (1) states that every input $m$ supplied by every origin $i$ directed to all services $s \in S$ in all terminals $j \in J$ must be compatible with the supply of this input $m$ at the given origin $i$. 
Constraint (2) states that the quantity of product $q$ from all terminals $j \in J$ must be equal or lower than the maximum demand of product $q$ at destination $k$. Equation (3) states that for each terminal $j$ and each service package $s$ the inbound flow of input $m$ sent to such terminal must be compatible with the nominal service capacity locally offered. Constraint (4) states that the total inputs $m$ sent from all origins $i$ to any given service $s$ in terminals $j$ must be compatible with the capacity of the corresponding terminal $j$.

Constraint (5) represents for each terminal, each input, each product, and each type of service the flow conservation equation indicating the equilibrium between all amounts received and sent from the corresponding terminals. Constraint (6) states a limit of $Z$ terminals to be opened, and the remaining constraints (7) through (8) and (9) indicate the non-negativity of the decision variables and the binary condition of the location variables.

\section{RESULTS OF THE CASE STUDY}

The case study has considered the volume of exported soybeans in the year 2004, and the sample was defined mainly by way of accessibility to basic data. The physical connections, portrayed in Figure 2, included six points of origin with corresponding supplies (Table 2), six potential transshipment ports (Table 3) with their nominal services and total capacities, and three ports of destination with their maximum demands (Table 4). The six selected points of origin are linked by railroad to potential ports, which does not exclude, as noted before, an extensive truck collection at the farms and the transshipment to the railroad terminal. These six points were selected by determining the largest centroid points of supply that are connected by railroad to the six main transshipment ports considered in the study. The three selected destination ports were Rotterdam - Holland; Hamburg - Germany; and Shanghai - China, and are representative of the most important destination ports to soybean supply chain. The cost coefficients as well as all parameters used in the case study are quite realistic for the sample elements considered. These cost elements represent average costs between trucks and railways tariffs and are available in Dubke (2006). No seasonality was considered in the model, but rather yearly averages.

In summary, the relevant sets of points for this case study are as follows:

I Set of cities or points of origin $i \in I=$ AAçailândia, Araguari, Campo Grande, Cuiabá, Dourados, Londrina\};

$J \quad$ Set of specialized terminals $j \in J=\{$ ITQ - Itaqui, TUB - Tubarão, SAT - Santos, PAR - Paranaguá, SFS - São Francisco do Sul, RG - Rio Grande\};

$K \quad$ Set of ports of destination $k \in K=\{$ Rotterdam, Hamburg, Shanghai $\}$;

$M \quad$ Set of inputs $m \in M=$ \{soybean ;

$Q \quad$ Set of products $q \in Q=$ \{soybean, soy meal, soy oil $\}$;

$S \quad$ Set of services $s \in S=$ \{warehousing, smashing, processing .

The model formulation was elaborated using AMPL, the modeling language mathematical programming (Fourer et al., 2003), and was applied using ILOG AMPL CPLEX SISTEM - MIP solver 8.0 (2002) with all default parameters in a computer Intel Core DUO 2GHz/1Gb RAM. The average processing time for each instance of the model was 10 seconds. 


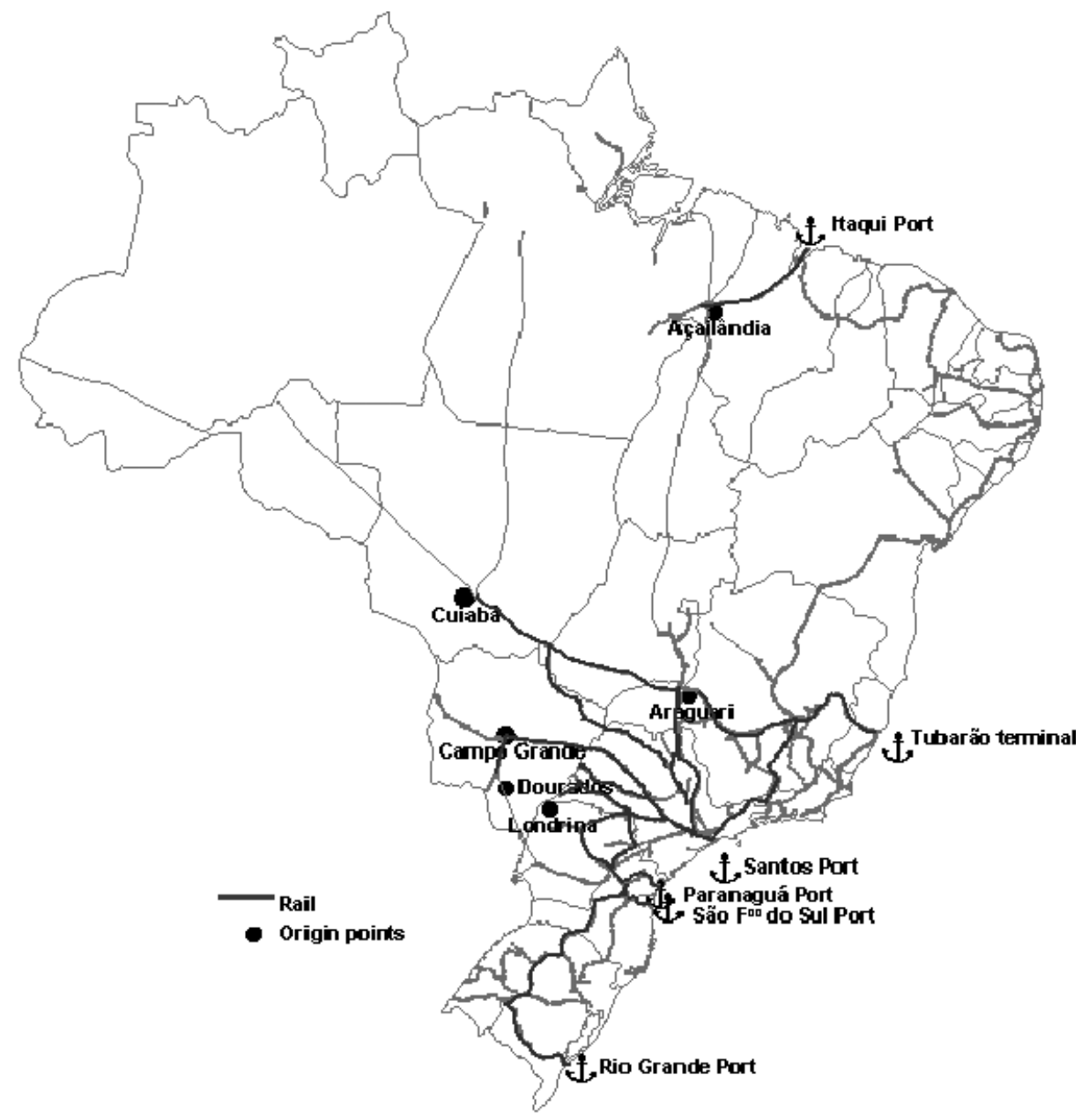

Figure 2 - Origin points and transshipment terminals. Source: Dubke (2006).

Table 2 - Set of origins of soybeans in Brazil - 2004 .

\begin{tabular}{|c|c|c|}
\hline $\begin{array}{c}\text { Origin } \\
\left(S_{i m}\right)\end{array}$ & $\begin{array}{c}\text { Cities } \\
(i)\end{array}$ & $\begin{array}{c}\text { Supply } \\
\text { (ton) }\end{array}$ \\
\hline $\mathrm{S}_{1}$ & Açailândia - PA & 70,000 \\
$\mathrm{~S}_{2}$ & Araguari - MG & 80,000 \\
$\mathrm{~S}_{3}$ & Campo Grande - MS & 300,000 \\
$\mathrm{~S}_{4}$ & Cuiabá - MT & 250,000 \\
$\mathrm{~S}_{5}$ & Dourados - MT & 200,000 \\
$\mathrm{~S}_{6}$ & Londrina - PR & 300,000 \\
\hline \multicolumn{2}{|c|}{ Total } & $1,200,000$ \\
\hline
\end{tabular}

Source: Dubke (2006). 
Table 3 - Nominal service and total capacity in specialized terminals - 2004.

\begin{tabular}{|c|c|c|c|c|}
\hline \multirow{2}{*}{$\begin{array}{c}\text { Specialized } \\
\text { terminals } \\
(j)\end{array}$} & \multicolumn{3}{|c|}{ Installed capacity to service $\left(w_{j s}\right)$} & \multirow{2}{*}{$\begin{array}{c}\text { Total } \\
\text { capacity } \\
\text { (ton) } W_{j}\end{array}$} \\
\hline & $\begin{array}{l}\text { Warehousing } \\
\text { (ton) }\end{array}$ & $\begin{array}{c}\text { Smashing } \\
\text { (ton) }\end{array}$ & $\begin{array}{l}\text { Processing } \\
\text { (ton) }\end{array}$ & \\
\hline ITQ & 100,000 & 100,000 & 50,000 & 250,000 \\
\hline TUB & 300,000 & 100,000 & & 400,000 \\
\hline SAT & 200,000 & 100,000 & 60,000 & 360,000 \\
\hline PAR & 400,000 & 280,000 & 100,000 & 780,000 \\
\hline SFS & 100,000 & 60,000 & 50,000 & 210,000 \\
\hline RG & 100,000 & 90,000 & 50,000 & 240,000 \\
\hline
\end{tabular}

Source: Dubke (2006).

Table 4 - Maximum demand at destinations $D_{k q}-2004$.

\begin{tabular}{|c|c|c|}
\hline $\begin{array}{c}\text { Destinations } \\
D_{k}\end{array}$ & $\begin{array}{c}\text { Products } \\
q\end{array}$ & $\begin{array}{c}\text { Max. demand } \\
\text { (ton) }\end{array}$ \\
\hline HAM & Soymeal & 960,000 \\
HAM & Soyoil & 240,000 \\
ROT & Soybean & $1,200,000$ \\
ROT & Soymeal & 960,000 \\
ROT & Soyoil & 240,000 \\
SHG & Soybean & $1,200,000$ \\
SHG & Soymeal & 960,000 \\
SHG & Soyoil & 240,000 \\
\hline \multicolumn{2}{|c|}{ Total } & $7,200,000$ \\
\hline
\end{tabular}

Source: Dubke (2006).

\subsection{Main results}

Table 5 summarizes the solutions for a varying number of terminals. It shows that it is economical to have more terminals, since restricting the model to $Z \leq 6$ yielded a solution of US\$241.9 million and $Z=6$ was proposed. In addition, all six terminals would operate with storage services but without smashing or processing, i.e., refining, as shown in the first row of Table 5 . Soy allocations from the origins to the terminals and from these to destination ports are presented in Tables 6 and 7.

By restricting to $Z \leq 5$ terminals, the model reduced the value of the objective function to US\$ 235.1 million, as shown in Table 5, opening five specialized terminals with warehousing services in Itaqui, Tubarão, Santos, Paranaguá and San Francisco do Sul, and with smashing services in the Santos terminal while no allocation was proposed to soy oil production. With the restriction $Z \leq 4$, the objective function resulted in US\$227.9 million and storage services were proposed in Itaqui, Tubarão, Santos and Paranaguá, smashing services in Tubarão and Santos, and no allocation was proposed to soy oil production. 
Table 5 - Results of $Z \leq 6$ specialized terminals.

\begin{tabular}{|c|c|c|c|c|c|}
\hline \multirow{3}{*}{$Z$} & \multicolumn{5}{|c|}{ F.O. results } \\
\hline & \multirow{2}{*}{ US\$ M } & \multirow{2}{*}{$Y_{j}$} & \multicolumn{3}{|c|}{$Y_{j}^{\text {serv }}$} \\
\hline & & & Warehousing & Smashing & Processing \\
\hline$Z \leq 6$ & 241,9 & ITQ, TUB, SAT, SFS, PAR, RG & ITQ, TUB, SAT, SFS, PAR, RG & & \\
\hline$Z \leq 5$ & 235,1 & ITQ, TUB, SAT, SFS, PAR & ITQ, TUB, SAT, SFS, PAR & SAT & \\
\hline$Z \leq 4$ & 227,9 & ITQ, TUB, SAT, PAR & ITQ, TUB, SAT, PAR & TUB, SAT & \\
\hline$Z \leq 3$ & 216,5 & TUB, SAT, PAR & TUB, SAT, PAR & TUB, SAT, PAR & \\
\hline$Z \leq 2$ & 189,0 & TUB, PAR & TUB, PAR & TUB, PAR & \\
\hline$Z=1$ & 115,2 & PAR & PAR & PAR & PAR \\
\hline
\end{tabular}

Note: ITQ (Itaqui), TUB (Tubarão), SAT (Santos), PAR (Paranaguá), SFS (São Francisco do Sul) and RG (Rio Grande). Source: Dubke (2006).

Table 6 - Soy allocation flow from origins to specialized terminals (ton).

\begin{tabular}{|c|c|c|c|c|c|c|}
\hline \multirow{2}{*}{ Origin points $(i)$} & \multicolumn{7}{|c|}{ Specialized terminals $(j)$} \\
\cline { 2 - 7 } & Itaqui & Tubarão & Santos & Paranaguá & S. Fco do Sul & Rio Grande \\
\hline Açailândia & 70,000 & 0 & 0 & 0 & 0 & 0 \\
\hline Araguari & 30,000 & 0 & 0 & 50,000 & 0 & 0 \\
\hline C. Grande & 0 & 0 & 0 & 200,000 & 100,000 & 0 \\
\hline Cuiabá & 0 & 0 & 0 & 150,000 & 0 & 100,000 \\
\hline Dourados & 0 & 200,000 & 0 & 0 & 0 & 0 \\
\hline Londrina & 0 & 100,000 & 200,000 & 0 & 0 & 0 \\
\hline
\end{tabular}

Note: Results for the case $Z \leq 6$ terminals. Source: Dubke (2006).

Table 7 - Soy allocation flow from specialized terminals to destinations (ton).

\begin{tabular}{|c|c|c|c|}
\hline Ports $(k)$ & Rotterdam & Hamburg & Shanghai \\
\hline Itaqui (ITQ) & 0 & 100,000 & 0 \\
\hline Tubarão (TUB) & 300,000 & 0 & 0 \\
\hline Santos (SAT) & 200,000 & 0 & 0 \\
\hline Paranaguá (PAR) & 400,000 & 0 & 0 \\
\hline S. Fco. Sul (SFS) & 0 & 100,000 & 0 \\
\hline Rio Grande (RG) & 0 & 100,000 & 0 \\
\hline
\end{tabular}

Results for the case $Z \leq 6$ terminals. Source: Dubke (2006).

Considering the restriction $Z \leq 3$, the model reduced the objective function to US\$216.5 million and suggested opening three specialized terminals in Tubarão, Santos and Paranaguá, offering warehousing and smashing services. For this situation, the model did not present allocations for soy oil production. Considering the restriction $Z \leq 2$ terminals, the model reduced the objective function to US\$ 189.0 million and proposed opening two specialized terminals in Tubarão and Paranaguá, offering warehousing and smashing packaged services. No allocation to soy oil production was proposed. 
For just one terminal, $Z=1$, Paranaguá would be the one chosen and would perform all three kinds of services, but the objective function would result in the much smaller amount of US\$ 115.2 million.

Table 6 describes the flow of soybeans from each of the six origins to each terminal for the case $Z=6$.

Table 7 shows the exports from each terminal to each destination. The table suggests that unless Asia pays higher tariffs exports will be only directed to Europe.

\subsection{Sensitivity analysis for capacity expansion}

Table 8 indicates the solution if the installed capacity in the selected maritime terminals were increased by $100 \%$. Such increase would affect the fixed costs considered in the model. Interestingly, if $Z$ is restricted to $Z \leq 6$, the solution would recommend $Z=4$ terminals (Itaqui, Tubarão, Santos, and Paranaguá), all operating with storage services. If $Z \leq 3$, the port of Santos would be discarded, while for $Z \leq 2$ the two ports would be Tubarão and Paranaguá. For $Z=1$, the only port selected would be Paranaguá, offering warehousing and smashing, but the value of the solution would be reduced expressively.

Table 8 - Sensitivity analysis for fixed costs and installed capacity.

\begin{tabular}{|c|c|c|c|c|c|}
\hline \multirow{3}{*}{$Z$} & \multicolumn{5}{|c|}{ F.O. results } \\
\hline & \multirow{2}{*}{ US\$ M } & \multirow{2}{*}{$Y_{j}$} & \multicolumn{3}{|c|}{$Y_{j}^{\operatorname{ser} v}$} \\
\hline & & & Warehousing & Smashing & Processing \\
\hline$Z \leq 6$ & 246,4 & ITQ, TUB, SAT, PAR & ITQ, TUB, SAT, PAR & & \\
\hline$Z \leq 5$ & 246,4 & ITQ, TUB, SAT, PAR & ITQ, TUB, SAT, PAR & & \\
\hline$Z \leq 4$ & 246,4 & ITQ, TUB, SAT, PAR & ITQ, TUB, SAT, PAR & & \\
\hline$Z \leq 3$ & 244,3 & ITQ, PAR, TUB & ITQ, PAR, TUB & & \\
\hline$Z \leq 2$ & 240,6 & TUB, PAR & TUB, PAR & & \\
\hline$Z=1$ & 197,1 & PAR & PAR & PAR & \\
\hline
\end{tabular}

Note: ITQ (Itaqui), TUB (Tubarão), SAT (Santos), PAR (Paranaguá), SFS (São Francisco do Sul) and RG (Rio Grande). Source: Dubke (2006).

Certainly, the production of grains is highly seasonal and so are prices, and transportation costs but the model has considered yearly averages. This seems reasonable since producers have the possibility of stocking the product awaiting more favorable conditions. Something similar also happens in the ports, which are able to retain stocks to smooth out the in and outflows of the products.

\subsection{Sensitivity analysis for transportation costs}

Figure 3 presents a sensitivity analysis for inbound and outbound costs. As can be observed, by reducing in $25 \%$ the transportation costs, the model improved its results (US\$261.8 million, compared to US\$2 241.9 million). When the transportation costs were raised by $25 \%$ and $50 \%$, 
the model decreased its objective function. For all cost changes the solution of the model is given by the same variables as presented in Table 5. In addition, Figure 3 shows the relative shift of each solution for each number of terminals $Z$.



Figure 3 - Sensitivity analysis for transportation costs. Source: Dubke (2006).

\subsection{Sensitivity analysis for prices}

Prices in the international market considered in the case study (US\$ 290/t for soy, US\$ 250/t for soy meal and US\$350/t for soy oil), have produced an objective function of US\$ 241.9 million for the system, according to Table 5. In order to assess the sensitivity, we have applied slight increases of $10 \%, 20 \%$ and $30 \%$ in prices, and the model produced objective functions of US\$ 276.7 million, US\$ 311.5 million and US\$ 415.9 million, respectively. Considering a price reduction of $10 \%, 20 \%$ and $50 \%$, the model decreased the objective function value to US\$ 207.1 million, US\$ 172.3 million, and US\$ 68.3 million, respectively, compared to the current solution. Figure 4 indicates the sensitivity to several different price changes and to the three different products: raw soybean, soy meal, and soy oil.

\section{CONCLUSIONS}

This work has initially outlined the economic importance of soybeans production for the Brazilian economy and also indicated the relevance of satisfying the world market demands. In fact, Brazil seems to be the only country able to generate large grain surpluses to feed a hungry world. Certainly, the unrestricted expansion of production raises strong criticism regarding the threats to the environment. However, extended areas in the interior of the country that have been degraded for inappropriate cattle raising activities along the past few hundred years might be 


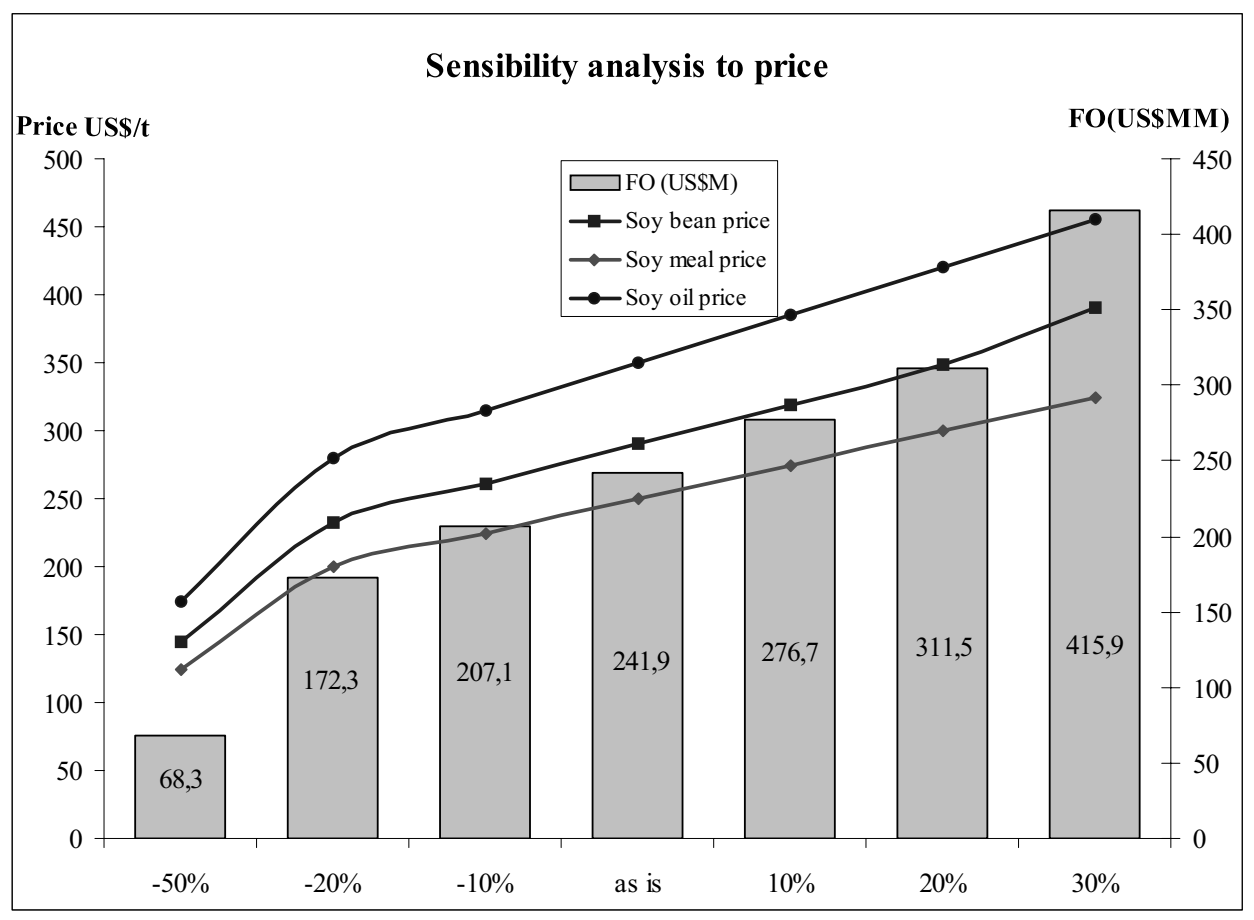

Figure 4 - Sensitivity analysis for prices. Source: Dubke (2006).

converted, without additional environment damages, into grain production, a more efficient and economically prosperous activity.

On the other hand, the new production frontiers are quite distant from the maritime ports from which the soybeans reach the international markets. The transportation costs are significantly high and they tend to offset the relative advantage resulting from high productivity, less capital costs, and low production costs. Therefore, the major problem that deserves priority is the reduction of the downstream logistics costs since the structure relies today mostly on old trucks and poorly paved roads. In this sense, the ports in the north, like Itaqui, represent a new opportunity, since they can be reached by railway and by rivers. Another problem currently overlooked is the transformation of the soy beans in more valuable products such as the soy oil and the soy meal. Therefore, short-term measures to face the infrastructure problems are: warehousing and further processing.

The main purpose of this work was the development of a location model for specialized terminals. The theoretical basis was the transshipment model combined with a multi-commodity, multi-facility capacitated location model. The study began with the concept of locating logistics platforms - as macro business units that add value to the product - to arrive at the problem of locating specialized terminals - as micro business units that add specialized services to logistics chains. Based on the proposed model, it is clearly possible to suggest the most appropriate ports to locate a specialized terminal that add value to the exported product by transforming raw 
soy grains into soy oil and soy meal. The objective is to maximize the profitability of exporters taking into consideration the balance between income, port costs, and inbound and outbound transportation costs.

The model's applicability was tested with realistic data from the supply chain of soybeans. Sensitivity evaluations regarding inbound and outbound transportations costs, investments, installed capacity and prices in international markets were also roughly examined. One important element was the sensitivity to the installed capacity, since the modeling, as expected, has considered average yearly capacity. Certainly, the soybean production is highly seasonal and so are prices, and transportation costs, specially the truck costs. However, producers and cooperatives have the possibility of stocking the product waiting for more favorable conditions, and also the ports may retain the product to balance the incoming and outcoming flows.

We hope that the present exploratory study might motivate more extended ones, supported by the country's strategic planning authorities, to make long range planning on logistics issues regarding the exports of grains. The idea is to amplify the study both in its extension in order to include all productive areas of the country, and all potential ports, as well as to tackle the problem of the transportation network planning evolution, including new roads, new railroads and river ways specially on the Amazon basin.

\section{ACKNOWLEDGEMENTS}

The authors would like to acknowledge several institutions that have granted support to this research. The first author would like to express her gratitude to CAPES, PUC-Rio, Instituto Federal do Espirito Santo - IFES and VALE, while the second author is grateful to the CNPq, that supported partially the research.

\section{REFERENCES}

[1] Ahuja R, Magnanti TL \& Orlin JB. 1993. Network flows. Prentice Hall, Inc., New Jersey.

[2] BNDES. 2004. BNDES SETORIAL. O ciclo da soja: Desempenho da cultura da soja entre 1961 e 2000. Rio de Janeiro, 20: 127-222.

[3] Brandeau M \& ChiU S. 1989. An overview of representative problems in location research. Management Science, 35(6): 645-674.

[4] Campbell J. 1993. One-to-many distribution with transshipments: an analytic model. Transportation Science, 27(4): 330-340.

[5] Canel C \& Khumawala BM. 1996. A mixed-integer programming approach for the international facilities location problem. International Journal of Operations \& Production Management, 16(4): 49-68.

[6] COnAB - Companhia Nacional de Abastecimento. 2008. Indicadores da agropecuária. Acessible at: <www.conab.gov.br>; accessed on July, 28.

[7] Crainic T \& LAPORTE G. 1997. Planning models for freight transportation. European Journal of Operational Research, 97: 409-438. 
[8] CVRD - Companhia Vale do Rio Doce, VAlE. 2005. Indústria da Soja e Farelo de Soja para Exportação. São Paulo, Technical report.

[9] De Paula SR \& Faveret Filho P. 2000. Panorama do Complexo da Soja. In: BNDES setorial. Special Edition. BNDES, Rio de Janeiro.

[10] Drezner R \& HAMAcher H. 2002 (Ed.). Facility location: applications and theory. Berlin: Verlag publishing.

[11] DuBKe AF. 2006. Modelo de localização de terminais especializados: um estudo de caso em corredores de exportação da soja. Doctoral Dissertation in Industrial Engineering. Programa de Pósgraduação em Engenharia Industrial, Pontifical Catholic University of Rio de Janeiro.

[12] Embrapa - Empresa Brasileira de Pesquisas Agropecuárias. 2002. Tecnologias de produção de soja - Paraná. Londrina: Embrapa Soja.

[13] Fourer R, GAY DM \& Kernighan BW. 2003. AMPL - A modeling language for mathematical programming. 2nd Edition, South Melbourne, Australia, Thompson.

[14] Hayut Y. 1981. Containerization and the load center concept. Economic Geography, 57(2): 160176.

[15] Harkness J \& ReVelle C. 2003. Facility location with increasing production costs. European Journal of Operational Research, 145: 1-13.

[16] HU TC. 1963. Multi-commodity network flows. Operations Research, 11(3): 344-360.

[17] ILOG AMPL CPLEX SYSTEM VERSion 8.0 - USER's GUIDE. FranCE. 2002. Accessible at: $<$ www.ampl.com $>$ accessed on 06/06/2005.

[18] IZQuIERDo R. 1994. Transportes - Un Enfoque Integral. Madrid, Colegio de Ingenieros de Caminos, Canales y Puertos.

[19] Konings JW. 1996. Integrated centers for the transshipment, storage, collection and distribution of goods: a survey of the possibilities for a high-quality intermodal transport concept. Transportation Policy, Great Britain, 3(1/2): 3-11.

[20] Matisziw T. 2005. Modeling transnational surface freight flow and border crossing improvement. Doctoral Dissertation in Geography, Ohio State University, USA.

[21] OWEN SH \& DASKIN M. 1998. Strategic facility location: a review. European Journal of Operational Research, 111: 423-447.

[22] Pirkul H \& Jayaraman V. 1998. A multi-commodity, multi-plant, capacitated facility location problem: formulation and efficient heuristic solution. Computers and Operations Research, Great Britain, 25(10): 869-878.

[23] ReVelle CS \& Eiselt HA. 2005. Location Analysis: A Synthesis and Survey. European Journal of Operational Research, 165: 1-19.

[24] REVELLE CS \& LAPORTE G. 1996. The plant location problem: new models and research prospects. Operations Research, 44(6): 864-874.

[25] Sharma D, Gosh D \& Mattison D. 2003. An application of goal programming with penalty functions to transshipment problems. International Journal of Logistics: Research and Applications, 6(3): 125-136. 
[26] SiqueIRA TW. 2004. O ciclo da soja: desempenho da cultura da soja entre 1961 e 2003. In: BNDES Setorial, Rio de Janeiro, 20: 127-222.

[27] Sidharan R. 1995. The capacitated plant location problem. European Journal of Operational Research, 87: 203-213.

[28] Souza MO, Marques DV, Souza GS \& Marra R. 2010. O Complexo da soja: aspectos descritivos e previsões. Pesquisa Operacional para o Desenvolvimento, 2(1): 56-86.

[29] USDA - United States Department of Agriculture. 2008. Acessible at: <www.usda.gov> accessed on $07 / 28 / 2008$.

[30] Tanigushi E, Noritake N, Yamada T \& Izumiatni T. 1999. Optimal size and location planning of public logistics terminals. Transportation Research E, 35(3): 207-222.

[31] Weber A. 1909. Über den Standort der Industrien (Alfred Weber's Theory of the location of industries). University of Chicago, 1929. 